\title{
Resíduos sólidos urbanos de Maceió/AL: análise da composição gravimétrica sob influências sazonais
}

A composição gravimétrica dos resíduos sólidos urbanos (RSU) é um importante instrumento de gestão, que possibilita conhecer as quantidades das frações de cada resíduo gerado. Neste sentido, o presente estudo teve como objetivo estimar as características dos resíduos gerados e destinados ao aterro municipal de Maceió/AL, quantificando e classificando-os como orgânicos, recicláveis e rejeitos, por regiões administrativas, além de avaliar características de variação no perfil dos resíduos que podem estar associadas à sazonalidade. Os dados sobre os resíduos foram obtidos por meio dos relatórios mensais, referentes às pesagens dos resíduos na chegada dos caminhões na balança do aterro sanitário, ao longo de um ano. Análises da composição gravimétrica dos resíduos foram efetuadas a fim de identificá-los em relação à sua classificação nas classes de: orgânicos, recicláveis e rejeitos, em 8 regiões administrativas, a partir dos roteiros de coleta de resíduos. Com base nas avaliações efetuadas constatou-se que, em média, os resíduos orgânicos representam $67,45 \%$, os materiais potencialmente recicláveis 20,32\%, e os rejeitos representam 12,23\% de todos os resíduos de Maceió. 0 estudo mostrou a média de massa percentual de materiais recicláveis de $18,06 \%$ e $22,58 \%$, do total de resíduos coletados, nos meses de junho, julho, agosto e novembro, dezembro 2017 e janeiro 2018 respectivamente, comprovando as diferenças relacionadas à sazonalidade e aos eventos festivos. Considerando os resultados obtidos, há necessidade de investir em educação, conscientização ambiental, informação e promoção do bem estar social, considerando o descarte e a separação adequada de resíduos sólidos domiciliares.

Palavras-chave: Material orgânico; Recicláveis; Rejeitos; Percentuais.

\section{Urban solid waste from Maceió/AL: analysis of gravimetric composition under seasonal influences}

\begin{abstract}
The gravimetric composition of solid urban waste (MSW) is an important management tool, which makes it possible to know the quantities of the fractions of each waste generated. In this sense, the present study aimed to estimate the characteristics of the waste generated and sent to the municipal landfill in Maceió/AL, quantifying and classifying them as organic, recyclable and waste, by administrative regions, in addition to evaluating characteristics of variation in the profile of the residues that may be associated with seasonality. The data on the residues were obtained through monthly reports, referring to the weighing of the residues at the arrival of the trucks on the scale of the landfill, over a year. Analyzes of the gravimetric composition of the residues were carried out in order to identify them in relation to their classification in the classes of: organic, recyclable and tailings, in 8 administrative regions, based on the guidelines for the collection of residues. Based on the evaluations carried out, it was found that, on average, organic waste represents $67.45 \%$, potentially recyclable materials $20.32 \%$, and tailings represent $12.23 \%$ of all waste in Maceió. The study showed the average mass percentage of recyclable materials of $18.06 \%$ and $22.58 \%$, of the total waste collected in the months of June, July, August and November, December 2017 and January 2018 respectively, proving the related differences seasonality and festive events. Considering the results obtained, there is a need to invest in education, environmental awareness, information and promotion of social well-being, considering the disposal and proper separation of household solid waste.
\end{abstract}

Keywords: Organic material; Recyclable; Waste; Percentage.

Topic: Planejamento, Gestão e Políticas Públicas Ambientais

Reviewed anonymously in the process of blind peer.

Claudionor de Oliveira Silva (iD)

Universidade do Vale do Taquari, Brasil

http://lattes.cnpq.br/7914499903341694

http://orcid.org/0000-0002-6566-0451

claudionor.silva@universo.univates.br

Odorico Konrad (iD)

Universidade do Vale do Taquari, Brasi

http://lattes.cnpq.br/9946679953072196

http://orcid.org/0000-0002-6968-7969

okonrad@univates.br

\section{Nélia Henriques Callado}

Universidade Federal de Alagoas, Brasil

http://lattes.cnpq.br/8042175776163111

http://orcid.org/0000-0002-2393-555X

nelia.callado@yahoo.com.br
Received: 14/03/2020

Approved: 21/04/2020

Liz Geise Santos de Araujo (iD)

Universidade Federal de Pernambuco, Brasi

http://lattes.cnpq.br/4373479527873700

http://orcid.org/0000-0003-0196-7064

lizaraujoeng@gmail.com

Camila Hasan

Universidade do Vale do Taquari, Brasil

http://lattes.cnpq.br/1967237941851023

http://orcid.org/0000-0002-0101-4039

chasan@universo.univates.br

\section{Referencing this:}

SILVA, C. O.; KONRAD, O.; CALLADO, N. H.; ARAUJO, L. G. S.; HASAN, C.. Resíduos sólidos urbanos de Maceió/AL: análise da composição gravimétrica sob influências sazonais. Revista Ibero Americana de Ciências Ambientais, v.11, n.3, p.426-439, 2020. DOI: http://doi.org/10.6008/CBPC2179-6858.2020.003.0033 


\section{INTRODUÇÃO}

O crescimento urbano, o desenvolvimento econômico e as mudanças das formas e dos modelos de consumo da população incidem em incremento da quantidade de resíduos sólidos urbanos (RSU) gerados que podem contribuir com vários problemas ambientais. Campos (2012) constatou que a geração de resíduos sólidos urbanos no Brasil tem crescido mais do que a própria população e o Produto Interno Bruto (PIB) do país, em 2002 a média era de 0,75 kg/hab. Dia, já em 2009 a média chegou a 0,96 Kg/hab. Dia. O mesmo autor revela que, em 2009, houve uma inflexão no crescimento do PIB enquanto a geração total de resíduos continuou aumentando. "Em relação à geração de RSU no Brasil, não existe uma perspectiva de diminuição no seu valor absoluto" (NASCIMENTO et al., 2015). Desses resíduos, "a matéria orgânica é um dos principais componentes dos resíduos sólidos" (DEUS et al., 2017).

Verifica-se, ainda, que grande parte dos resíduos gerados no país não têm coleta regulamentada nem destinação adequada. Embora a Abrelpe (2016) tenha observado avanço na cobertura de coleta nas regiões brasileiras, destacando que a região sudeste continua respondendo por aproximadamente $52,7 \%$ do total, apresentando o maior percentual de cobertura dos serviços de coleta do país.

Segundo informações da Abrelpe (2016), a população brasileira apresentou um crescimento de $0,8 \%$ entre 2015 e 2016, entretanto a geração per capita de RSU registrou queda de quase 3\% no mesmo período. A geração total de resíduos chegou a 214.405 Ton/dia de RSU gerados no país. A destinação correta dos resíduos sólidos urbanos (RSU) é um grande desafio da sociedade brasileira. Podemos destacar como marco legal a Política Nacional de Resíduos Sólidos (PNRS), instituída pela Lei № 12.305/2010, em que é reunido o conjunto de princípio, objetivos, diretrizes, instrumentos, metas e ações para a gestão integrada de resíduos sólidos urbanos (BRASIL, 2010).

A composição e a quantidade de resíduos podem variar de uma localidade para outra em função dos níveis de reanda e a sazonalidade, (OZCAN et al., 2016), dos níveis tecnológico, sanitários e cultural (FEAM, 2019). “O estudo gravimétrico é de extrema importância, para que o município consiga dimensionar e buscar soluções para os problemas relacionados aos resíduos sólidos, assim como, planejar ações que visem sua minimização" (FEAM, 2019), avaliação da gestão dos resíduos (BEZERRA et al., 2019).

Maceió apresentou uma produção diária de aproximadamente 1.141,11 toneladas de resíduos no período estudado (PERS, 2016), configurando-se como o único município do estado de Alagoas com geração de RSU acima de 1.000 toneladas diárias, o que sugere seu posicionamento como principal gerador de resíduos do estado. Contudo, observa-se que a coleta ainda necessita da aplicação de técnicas e tecnologias que atendam ao público de acordo com as suas especificidades, sejam urbanas, rurais, comerciais ou industriais, observando os critérios sociais, econômicos e ambientais.

As características dos resíduos sólidos podem ser reunidas em três grupos, de acordo com suas propriedades biológicas, químicas e físicas. Destes três grupos, o que mais influência no sistema de coleta e disposição final é o que contempla as características físicas, cujas propriedades se relacionam com o volume, a massa, teor de umidade e consequente classificação dos resíduos. Neste contexto, o presente estudo teve 
como objetivo avaliar as características dos resíduos gerados e destinados ao aterro municipal de Maceió/AL, quantificando e classificando-os como orgânicos, recicláveis e rejeitos, por regiões administrativas, além de avaliar características de variação no perfil dos resíduos que podem estar associadas à sazonalidade.

\section{MATERIAIS E MÉTODOS}

\section{Análise da geração de resíduos sólidos}

Na primeira etapa do estudo, com objetivo de analisar o quantitativo total de resíduos gerados e a produção per capita, foi identificada a quantidade de resíduos sólidos depositada no aterro sanitário de Maceió. Os dados sobre os resíduos foram obtidos por meio dos relatórios mensais, referentes às pesagens dos resíduos na chegada dos caminhões na balança do aterro sanitário, e dos relatórios da Superintendência de Limpeza Urbana de Maceió (SLUM), cujo período abrange os meses de janeiro a dezembro de 2017. Os dados de população para o cálculo da geração per capita foram obtidos por meio dos indicadores de população estimada (IBGE, 2017). Além disso, houve consulta de dados disponibilizados no Ministério das Cidades, por meio do Diagnóstico do Manejo dos Resíduos Sólidos Urbanos, edição de 2016.

A análise dos dados foi por meio do seu conteúdo (BARDIN, 2011) e dos documentos existentes, que, de acordo com Silva et al. (2009), são um "método de investigação da realidade social", pois não "traz uma única concepção filosófica de pesquisa, [e] pode ser utilizada tanto nas abordagens de natureza positivistas como também naquelas de caráter compreensivo, com enfoque mais crítico".

\section{Seleção de bairros a partir de roteiros de coleta de resíduos}

Segundo o plano diretor vigente (2009), Maceió está dividida em 50 bairros, que, por sua vez, compõem a malha de 8 regiões administrativas municipais. Esta etapa constituiu-se, portanto, na seleção de um conjunto de bairros pertencentes à cidade de Maceió, com objetivo de obter uma amostra capaz de representar os resíduos produzidos em toda a cidade. Para realização da composição gravimétrica dos resíduos foi realizada a escolha de bairros a partir de roteiros de coleta de resíduos, onde os bairros foram juntados por serem bairros vizinhos e tem seus resíduos coletados conjuntamente pelos mesmos caminhões compactadores, por isso, foram analisados conjuntamente, dentro de cada região administrativa que compõe a cidade.

Na RA1 foi selecionado o roteiro que compões os bairros, Pajuçara, Ponta Verde, Ponta da Terra; na RA2, Trapiche da Barra, Pontal da Barra; RA3, Jardim Petrópolis, Canaã, Santo Amaro; RA4, Chã da Jaqueira, Petrópolis, Chã de bebedouro, Santa Amélia; RA5, Jacintinho, Feitosa, São Jorge; RA6, Antares, Benedito Bentes; RA7, Cidade Universitária, Santos Dumont; RA8, Jacarecica, Guaxuma, Garça Torta, Riacho Doce, Pescaria, Ipioca. As coletas são realizadas por duas empresas: a Limpel, com $40 \%$ das coletas, e a Viva Ambiental, com 60\%. A figura 1 apresenta a localização geográfica das regiões administrativas de Maceió. 


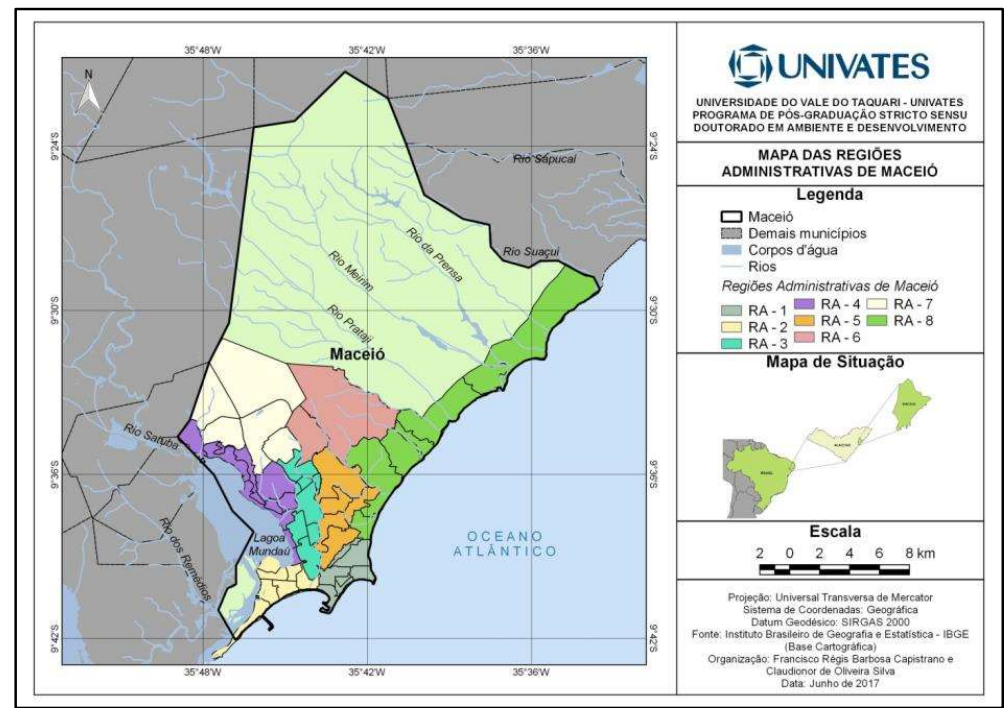

Figura 1: Localização geográfica das regiões administrativas de Maceió

\section{Determinação do período de frequência}

A meta adotada para a frequência de coleta de dados e de realização dos ensaios em 2017 foi uma por cada roteiro selecionada de cada RA, no total parcial de 16 amostras, nos meses de junho, julho e agosto; uma segunda coleta nos meses de novembro, dezembro 2017 e janeiro 2018, totalizando 32 amostras. A escolha deste período de estudo objetivou possibilitar a análise da influência da sazonalidade nas propriedades dos resíduos, comparando dois períodos com características climáticas bastante distintas: época de chuvas e época de seca. As coletas para a realização dos ensaios aconteceram na Central de Tratamento de Resíduos (CTR) de Maceió.

\section{Realização dos ensaios de campo}

Por meio da identificação da classe e da massa dos resíduos avaliados em cada amostra foi determinada a sua composição gravimétrica, empregando o método do quarteamento, aplicado também por Melo (2007), Tavares (2008), Konrad et al. (2010), Soares (2011), Resende et al. (2013), Gomes et al. (2016), Oliveira et al. (2017).

\section{Peso específico aparente}

A determinação do peso específico foi obtida por meio da amostra descarregada pelo caminhão coletor na sua chegada ao aterro sanitário (aproximadamente 1 tonelada), em um local previamente preparado (local limpo com lona de $2 \mathrm{~m} \times 2 \mathrm{~m}$ estendida). Após, aproximadamente $400 \mathrm{~kg}$ de lixo ainda ensacados foram pesados em recipiente de volume conhecido (FIGURA 1). Cabe salientar que a quantidade de $400 \mathrm{~kg}$ foi também adotada por outros autores que realizaram ensaios semelhantes (TAVARES, 2008; SOARES, 2011). Em relação à determinação da densidade, todas as amostras analisadas foram retiradas de veículos compactadores, cujo grau de compactação foi amenizado no ato da descarga do conteúdo do veículo.

A densidade da amostra foi calculada pela relação entre a sua massa e o seu volume, de acordo com 
a equação 1.

$$
\rho=\frac{M-\mathrm{Mr}}{V}\left(\mathrm{~kg} / \mathrm{m}^{3}\right)
$$

Onde:

$P$ corresponde à densidade;

$M$ é o símbolo utilizado para a massa de resíduos; Mr é a correspondência para a massa do recipiente; $\checkmark$ representa o volume do recipiente.

\section{Composição gravimétrica}

Os ensaios para determinação da composição gravimétrica dos resíduos iniciaram com o rompimento dos sacos das amostras de $400 \mathrm{~kg}$ utilizadas na determinação da densidade. Após este procedimento, o conteúdo foi homogeneizado manualmente com auxílio de pá e enxada. Depois de homogeneizada, a amostra foi dividida em 4 partes iguais, sendo desprezadas duas quartas-partes, de preferência as opostas, restando duas parcelas de $100 \mathrm{~kg}$, finalizando o primeiro quarteamento. Em seguida, as duas parcelas de 100 $\mathrm{kg}$ foram misturadas novamente, iniciando-se o segundo quarteamento.

Do mesmo modo, a amostra foi dividida em quatro partes, com $50 \mathrm{~kg}$ cada. Duas quartas-partes, vis$\grave{a}$-vis, foram novamente desprezadas, resultando em apenas duas parcelas de $50 \mathrm{~kg}$ cada. Finalmente, misturaram-se as parcelas restantes e sua soma deu origem à amostra trabalhada pelo método de determinação da composição física, a partir da segregação e pesagem dos principais componentes que constituíram os resíduos avaliados. A pesagem de cada grupo de componentes foi registrada em uma planilha para análise gravimétrica. Em seguida, o percentual de cada componente presente no resíduo foi determinado por meio da indicação de sua massa em relação à massa total da amostra, equação 2 .

$$
\mathrm{CG}(\%)=\frac{\mathrm{Mc}}{\mathrm{Mt}} \times 100
$$

Onde:

CG corresponde à composição gravimétrica, em porcentagem,

Mc é a massa do componente, em quilogramas, Mt representa a massa total, também em quilogramas.

\section{RESULTADOS E DISCUSSÃO}

\section{Análise dos resíduos sólidos}

Os resíduos destinados ao aterro sanitário municipal, de acordo com as planilhas de controle, são classificados como resíduos de Classe II A. Os resíduos de classe IIA, podem ter propriedades tais como: biodegradabilidade, combustibilidade ou solubilidade em água (NBR 10004 - ABNT, 2004). O levantamento de dados, com base no quantitativo de resíduos registrados nas planilhas das pesagens dos caminhões em balança do aterro sanitário, está ilustrado na Figura 2.

Avaliando os dados, percebe-se que a quantidade de material (em $\mathrm{kg}$ ) variou ao longo dos meses, aparentando-se mais estável nos meses de abril a junho, período também onde é possível constatar que a quantidade de resíduos gerada foi menor. Gomez et al. (2008), em trabalho semelhante em chihuahua, México, verificou diminuição de resíduos nos meses de março a agosto. 


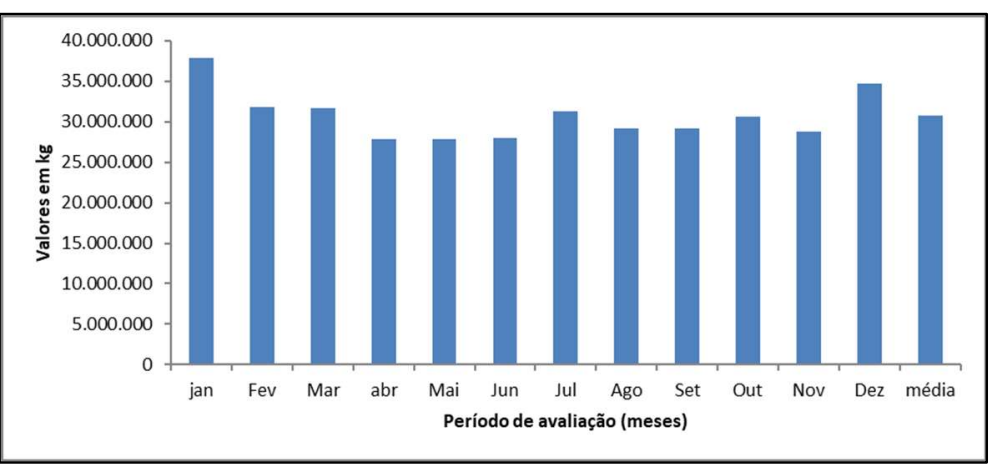

Figura 2: Quantidade de resíduos de Classe IIA em kg, de janeiro a dezembro de 2017.

Considerando o mês de janeiro, verificou-se, aumento de geração de resíduos, o que pode ser atribuído a determinados eventos, como as festas populares e as férias escolares, que ocorrem durante o mês de janeiro. $\mathrm{O}$ aumento da produção de resíduos no mês de dezembro pode ser devido ao aumento de pessoas no comércio, devido às compras de final de ano e período festivos. Outros fatores podem interferir nesses dados, conforme estudo realizado por Franco (2012), que sugere que as diferenças de estilo de vida e padrões de consumo da população são evidenciadas quando os resíduos sólidos urbanos são relacionados com os portes das cidades".

Maceió tem uma população estimada de 1.021 .129 e a geração per capita diária de resíduos ( $\mathrm{kg} / \mathrm{habitante} / \mathrm{dia}$ ) verificada foi de 0,98 kg/hab./dia, mantendo-se acima da média do Diagnóstico do Manejo de Resíduos Sólidos Urbanos, do ano de 2016, que aponta a média nacional de 0,94 kg/hab./dia (BRASIL, 2018).

Cabe destacar que as regiões norte e nordeste apresentaram queda percentual na média de RSU. Na região norte, em 2015 , a média per capita era de 1,13 e passou para $0,99 \mathrm{~kg} / \mathrm{hab}$./dia, decrescendo $12 \%$. Já no Nordeste, no ano de 2016, a média era de 1,22 e caiu para 1,10 kg/hab./dia, decrescendo, dessa forma, 10\%. Verifica-se, também, uma queda de aproximadamente $4 \%$ nas demais regiões brasileiras (BRASIL, 2018). Em outras regiões do país, foi possível identificar a geração per capita diária de resíduos sólidos variando entre 0,46 e 0,64 kg/hab./dia (KONRAD et al., 2010; FRANCO, 2012; RESENDE et al., 2013). Constatase, assim, que, nesses estudos, a massa gerada ficou abaixo da média nacional.

\section{Análise da composição gravimétrica}

As tabelas 1 e 2, apresentam os resultados da composição gravimétrica nas 8 regiões administravas, das análises realizadas em junho, julho, agosto e novembro, dezembro de 2017 e janeiro 2018.

Tabela 1: Composição gravimétrica nas RAs de Maceió em junho, julho e agosto de 2017.

\begin{tabular}{|l|l|l|l|l|l|l|l|l|l|}
\hline Material & RA-01 & RA-02 & RA-03 & RA-04 & RA-05 & RA-06 & RA-07 & RA-08 & Média \\
\hline Papel & $6,00 \%$ & $0,50 \%$ & $3,00 \%$ & $1,50 \%$ & $2,00 \%$ & $4,50 \%$ & $4,00 \%$ & $5,50 \%$ & $3,38 \%$ \\
\hline Papelão & $4,00 \%$ & $4,50 \%$ & $4,10 \%$ & $4,00 \%$ & $1,50 \%$ & $3,50 \%$ & $8,00 \%$ & $2,50 \%$ & $4,01 \%$ \\
\hline Madeira & & & $1,10 \%$ & & $0,50 \%$ & $4,70 \%$ & $0,75 \%$ & $5,00 \%$ & $2,41 \%$ \\
\hline Trapos & $2,80 \%$ & $13,80 \%$ & $3,40 \%$ & $2,70 \%$ & $2,00 \%$ & $4,10 \%$ & $2,35 \%$ & $2,60 \%$ & $4,22 \%$ \\
\hline Couros & & & & $0,30 \%$ & $0,30 \%$ & $0,20 \%$ & $0,20 \%$ & $0,20 \%$ & $0,24 \%$ \\
\hline Borracha & & & $3,50 \%$ & $1,20 \%$ & & $0,30 \%$ & $2,00 \%$ & $0,30 \%$ & $1,46 \%$ \\
\hline Plástico Duro & $2,00 \%$ & $2,50 \%$ & $2,90 \%$ & $2,00 \%$ & $0,50 \%$ & $2,00 \%$ & $3,50 \%$ & $2,50 \%$ & $2,24 \%$ \\
\hline Plástico Mole & $8,00 \%$ & $2,90 \%$ & $7,50 \%$ & $11,00 \%$ & $4,50 \%$ & $8,00 \%$ & $4,50 \%$ & $1,35 \%$ & $5,97 \%$ \\
\hline Latas de alumínio & & & & & & $0,10 \%$ & & & $0,10 \%$ \\
\hline
\end{tabular}




\begin{tabular}{|l|l|l|l|l|l|l|l|l|l|}
\hline Metais Ferrosos & $1,25 \%$ & $0,60 \%$ & $3,00 \%$ & $0,30 \%$ & $1,50 \%$ & $0,40 \%$ & $0,25 \%$ & $0,60 \%$ & $0,99 \%$ \\
\hline Metais não ferrosos & $0,20 \%$ & $0,32 \%$ & $0,50 \%$ & $0,30 \%$ & $1,50 \%$ & $0,90 \%$ & $0,30 \%$ & $2,50 \%$ & $0,82 \%$ \\
\hline Vidro & & $0,63 \%$ & $0,50 \%$ & & $2,00 \%$ & $0,60 \%$ & $0,20 \%$ & $1,25 \%$ & $0,86 \%$ \\
\hline Terras e Similares & $0,90 \%$ & $0,80 \%$ & & & $4,10 \%$ & $0,30 \%$ & $0,50 \%$ & $0,50 \%$ & $1,18 \%$ \\
\hline Fraldas Higiênico e e & $3,00 \%$ & $1,50 \%$ & $14,50 \%$ & $8,00 \%$ & $6,10 \%$ & $9,00 \%$ & $1,00 \%$ & $2,50 \%$ & $5,70 \%$ \\
\hline $\begin{array}{l}\text { Papel } \\
\text { absorvente }\end{array}$ & $0,20 \%$ & $0,10 \%$ & $0,30 \%$ & $0,10 \%$ & $0,70 \%$ & $0,15 \%$ & $0,40 \%$ & $0,27 \%$ \\
\hline Matéria Orgânica & $71,65 \%$ & $71,75 \%$ & $55,90 \%$ & $68,40 \%$ & $73,40 \%$ & $60,70 \%$ & $72,30 \%$ & $72,30 \%$ & $68,30 \%$ \\
\hline Total & $100,00 \%$ & $100,00 \%$ & $100,00 \%$ & $100,00 \%$ & $100,00 \%$ & $100,00 \%$ & $100,00 \%$ & $100,00 \%$ & $100,00 \%$ \\
\hline
\end{tabular}

Tabela 2: Composição gravimétrica nas RAs de Maceió em novembro, dezembro de 2017e janeiro 2018.

\begin{tabular}{|l|l|l|l|l|l|l|l|l|l|}
\hline Material & RA-01 & RA-02 & RA-03 & RA-04 & RA-05 & RA-06 & RA-07 & RA-08 & Média \\
\hline Papel & $4,50 \%$ & $3,80 \%$ & $4,50 \%$ & $5,30 \%$ & $6,90 \%$ & $0,50 \%$ & $6,50 \%$ & $5,50 \%$ & $4,69 \%$ \\
\hline Papelão & $5,60 \%$ & $3,90 \%$ & $5,50 \%$ & $7,80 \%$ & $6,50 \%$ & $4,50 \%$ & $6,00 \%$ & $3,50 \%$ & $5,41 \%$ \\
\hline Madeira & $0,10 \%$ & $2,00 \%$ & & $0,20 \%$ & $0,25 \%$ & $0,50 \%$ & $0,60 \%$ & & $0,61 \%$ \\
\hline Trapos & $3,80 \%$ & $4,10 \%$ & $7,50 \%$ & $4,10 \%$ & $3,90 \%$ & $10,80 \%$ & $3,75 \%$ & $2,30 \%$ & $5,03 \%$ \\
\hline Couros & $0,20 \%$ & $0,20 \%$ & $0,10 \%$ & $0,30 \%$ & $0,20 \%$ & $1,00 \%$ & $0,25 \%$ & $0,50 \%$ & $0,34 \%$ \\
\hline Borracha & $0,30 \%$ & $0,10 \%$ & $0,30 \%$ & $0,50 \%$ & $0,25 \%$ & $0,20 \%$ & $1,00 \%$ & $0,60 \%$ & $0,41 \%$ \\
\hline Plástico Duro & $2,10 \%$ & $4,05 \%$ & $6,20 \%$ & $4,20 \%$ & $3,70 \%$ & $4,50 \%$ & $4,90 \%$ & $3,00 \%$ & $4,08 \%$ \\
\hline Plástico Mole & $3,30 \%$ & $6,92 \%$ & $7,70 \%$ & $5,40 \%$ & $5,80 \%$ & $6,45 \%$ & $5,90 \%$ & $1,95 \%$ & $5,43 \%$ \\
\hline Latas de alumínio & $0,25 \%$ & $0,13 \%$ & $0,10 \%$ & $0,10 \%$ & $0,20 \%$ & & & $0,05 \%$ & $0,14 \%$ \\
\hline Metais Ferrosos & $0,30 \%$ & $0,80 \%$ & $1,60 \%$ & $1,40 \%$ & $2,62 \%$ & $1,25 \%$ & $0,70 \%$ & $2,00 \%$ & $1,33 \%$ \\
\hline Metais não ferrosos & $0,25 \%$ & $0,40 \%$ & $0,20 \%$ & $0,75 \%$ & $0,80 \%$ & $0,80 \%$ & $1,20 \%$ & $1,00 \%$ & $0,68 \%$ \\
\hline Vidro & $1,25 \%$ & $1,25 \%$ & $1,00 \%$ & $0,70 \%$ & $1,08 \%$ & $0,20 \%$ & $0,75 \%$ & $0,65 \%$ & $0,86 \%$ \\
\hline Terras e Similares & & $0,40 \%$ & $0,25 \%$ & & $0,50 \%$ & $0,30 \%$ & $0,45 \%$ & $0,95 \%$ & $0,48 \%$ \\
\hline Fraldas & $4,55 \%$ & $2,60 \%$ & $4,50 \%$ & $4,00 \%$ & $2,40 \%$ & $4,70 \%$ & $3,05 \%$ & $3,80 \%$ & $3,70 \%$ \\
\hline $\begin{array}{l}\text { Papel Higiênico } \\
\text { absorvente }\end{array}$ & $0,20 \%$ & $0,20 \%$ & $0,30 \%$ & $0,85 \%$ & $0,70 \%$ & $0,45 \%$ & $0,75 \%$ & $0,75 \%$ & $0,53 \%$ \\
\hline Matéria Orgânica & $68,70 \%$ & $69,30 \%$ & $60,50 \%$ & $63,90 \%$ & $64,40 \%$ & $63,70 \%$ & $63,70 \%$ & $74,40 \%$ & $66,08 \%$ \\
\hline Total & $100,00 \%$ & $100,00 \%$ & $100,00 \%$ & $100,00 \%$ & $100,00 \%$ & $100,00 \%$ & $100,00 \%$ & $100,00 \%$ & $100,00 \%$ \\
\hline
\end{tabular}

\section{Características dos resíduos sólidos por sazonalidade}

\section{Resíduos orgânicos}

Avaliando os dados das Tabelas 1, 2 e 3, com base na sazonalidade e na variabilidade dos resíduos encontrados na composição gravimétrica, constatou-se que a média de massa percentual de matéria orgânica de origem doméstica decresceu nas análises realizadas: o valor foi de 68,30\% em junho, julho e agosto, enquanto em novembro, dezembro 2017 e janeiro 2018, o valor foi de 66,60\%. Observa-se, desse modo, que os períodos de maiores índices pluviométricos coincidem com os maiores percentuais de matéria orgânica.

Nos meses de junho, julho e agosto, as regiões administrativas com maiores índices de matéria orgânica de origem doméstica foram as RAs 5, 8 e 7, com valores de 73,40\%, 72,30\% e 72,30\%, respectivamente. Essa diferença pode ser explicada pela ocorrência de chuvas no período do estudo, o que torna os resíduos mais úmidos e pesados.

De acordo com os resultados obtidos, observa-se que a média de matéria orgânica presente nas amostras avaliadas nos meses de junho, julho, agosto e novembro, dezembro 2017 e janeiro 2018 foi de 67,45\%. Em estudos realizado por Ramachandra et al. (2018), Al-Khatib et al. (2010) e Resende et al. (2013), foram encontradas as médias de matéria orgânica de $82,0 \% 65,1 \%$ e de $49,4 \%$, respectivamente.

Destaca-se que o percentual elevado de matéria orgânica ocupa espaços significativos nos aterros sanitários, diminuindo a sua vida útil. Segundo Gomes et al. (2015), o encaminhamento da matéria orgânica 
para compostagem possibilita a redução das emissões gasosas e liquidas. Os descartes inadequados, mesmo em cidades que contam com programas de coleta seletiva, diminui a quantidade de materiais passíveis de aproveitamento. No caso dessa pesquisa, o maior índice é o de matéria orgânica e de materiais recicláveis, que ainda são desprezados em grande escala. A baixa participação da população na separação desses materiais contribui para o encarecimento da coleta e do seu destino final.

Tabela 3: Material orgânico das RAs de Maceió.

\begin{tabular}{|l|l|l|l|}
\hline RAs & Jun, Jul, Ago & Nov, Dez, Jan & Média \\
\hline RA 1 & $71,65 \%$ & $72,90 \%$ & $72,28 \%$ \\
\hline RA 2 & $71,75 \%$ & $69,30 \%$ & $70,53 \%$ \\
\hline RA 3 & $55,90 \%$ & $60,50 \%$ & $58,20 \%$ \\
\hline RA 4 & $68,40 \%$ & $63,90 \%$ & $66,15 \%$ \\
\hline RA 5 & $73,40 \%$ & $64,40 \%$ & $68,90 \%$ \\
\hline RA 6 & $60,70 \%$ & $63,70 \%$ & $62,20 \%$ \\
\hline RA 7 & $72,30 \%$ & $63,70 \%$ & $68,00 \%$ \\
\hline RA 8 & $72,30 \%$ & $74,40 \%$ & $73,35 \%$ \\
\hline & $68,30 \%$ & $66,60 \%$ & $67,45 \%$ \\
\hline
\end{tabular}

\section{Materiais recicláveis}

Nos meses de junho, julho e agosto, foi possível identificar nas 8 RAs a média de $18,06 \%$ de massa percentual dos materiais potencialmente recicláveis. Em estudo semelhante, porém em outra região do país, foi possível identificar "na coleta regular materiais potencialmente recicláveis $28 \%$ (em massa) e do total dos resíduos" (KONRAD et al., 2010).

Os materiais que mais se destacaram foram o plástico mole $(5,97 \%)$, o papelão $(4,01 \%)$, o papel $(3,38 \%)$ e plástico duro $(2,24 \%)$. O valor elevado de plástico mole pode ser explicado pelo seu uso intenso em lojas, supermercados e lojas de conveniências. Os catadores revelaram que, devido ao seu preço baixo de mercado, sua coleta não se torna atraente para os catadores. Em estudo sobre a geração diária de resíduos, o plástico representou $9 \%$ da amostra, por isso percebe-se a necessidade de "existirem políticas estratégicas e participação comunitária para redução na fonte e melhor reciclagem de resíduos" (ADENIRAN et al., 2017).

O papelão, mesmo com destaque na composição de materiais recicláveis, obteve menor valor na análise feita em dezembro, ainda que observado o aumento da umidade desses materiais no mês de agosto, devido ao período de chuvas. Projetos, nesse caso, podem reduzir gastos dos munícipes e aumentar a sua renda com o aproveitamento dos materiais recicláveis. O elevado percentual de papel na amostra pode ser explicado pelo retorno das atividades escolares após o período de recesso escolar. O plástico duro representou em junho, julho e agosto, $2,24 \%$ dos materiais potencialmente recicláveis, no período de novembro, dezembro 2017 e janeiro 2018, o valor foi de 4,08\%. A redução do valor no período junho, julho e agosto, podem ser atribuídos pode ser atribuído às coletas feitas por catadores em pontos específicos para coleta de materiais ou nas lixeiras implantadas nas calçadas da cidade.

Os materiais que tiveram menores índices nas amostras foram a latas de alumínio $(0,10 \%)$, metais não ferrosos $(0,82 \%)$, vidro $(0,86 \%)$ e metais ferrosos $(0,99 \%)$. Constata-se, portanto, que o percentual de latas de alumínio é baixo, provavelmente em função do preço atraente de comercialização. Destaca-se, 
ainda, que as latas de alumínio, mesmo somadas aos materiais não ferrosos, totalizaram menos que $1 \%$ $(0,92 \%)$.

A presença de vidro e de materiais ferrosos não apresentaram índices elevados nas amostras. Uma possível causa é a sua substituição por embalagens plásticas, de papelão e/ou de metal. O vidro possui reciclagem desenvolvida e de fácil comercialização, o que torna seu ciclo de vida 100\% reciclável. Destaca-se que 4,86\% das embalagens de vários produtos têm sido substituídas por embalagens celulósicas (35,05\%), plásticas (37,47\%) e/ou de metal (16,03\%) (LANDIM et al., 2016).

Com isto, verifica-se a necessidade de consolidação de iniciativas que viabilizem o uso do vidro na cadeia produtiva, incentivando o processo de reuso, de reciclagem, de logística reversa e de aproveitamento adequado dos materiais descartados. Nos meses de novembro, dezembro de 2017 e janeiro 2018 foi possível identificar nas 8 regiões administrativas a média de 22,58\% de massa percentual dos materiais potencialmente recicláveis. Em estudo semelhante foi possível identificar a geração de materiais potencialmente recicláveis em variações entre $25 \%$ e $31,8 \%$ do total dos resíduos (RESENDE et al., 2013; GOMES et al., 2016; OLIVEIRA et al., 2017).

Os materiais que mais se destacaram foram o plástico mole $(5,43 \%)$, o papelão $(5,41 \%)$, o papel $(4,69 \%)$ e o plástico duro (4,08\%). O plástico mole teve uma pequena redução em relação aos meses de junho, julho e agosto, contudo foi o material que mais se destacou dentre os recicláveis do mês de dezembro. A elevada quantidade de papelão pode ser explicada pelo período de aquecimento do comércio no final de ano. Quanto ao papel, as vendas de embalagens de presentes e o início do processo de compra de material escolar podem ter influenciado em sua média.

Quanto ao plástico duro, durante os meses de junho, julho e agosto, o motivo pode ter sido devido o aumento do uso de embalagens de produtos de limpeza e de refrigerantes em períodos festivos, como a época de final de ano. Os eventos sazonais podem, portanto, influenciar na composição dos resíduos e, entre outros fatores, o clima, que por sua vez, devem ser analisadas ao longo de um ano (GALLARDO et al., 2016).

Dentre os materiais que tiveram menor destaque no volume total das amostras, novamente verificou-se as latas de alumínio (material não ferroso), os metais não ferrosos, os vidros e os metais ferrosos, com percentuais de $0,14 \%, 0,68 \%, 0,86 \%$ e $1,33 \%$, respectivamente. Os percentuais desses materiais encontrados nas análises realizadas são pouco representativos.

A lata de alumínio é um dos itens mais procurados da coleta seletiva, pelos catadores de materiais recicláveis. Eles são retirados dos caminhões de lixo, das lixeiras nas ruas e de eventos festivos, ainda que sua produção possa variar de acordo as estações do ano. Ramachandra et al. (2018), em seu trabalho sobre caracterização gravimétrica, identificou a geração de alumínio de $2 \%$ dentre os materiais potencialmente recicláveis. Salienta-se que esse elemento pode estar inserido em outros materiais, como panelas e seus cabos, entre outros (Tabela 4).

No presente estudo, de acordo com as amostras analisadas, a média de massa percentual de materiais recicláveis em Maceió foi de 18,06\% do total de resíduos coletados em junho, julho e agosto e de 22,58\% na coleta de dados do mês de novembro, dezembro 2017 e janeiro de 2018 comprovando as 
diferenças relacionadas à sazonalidade e aos eventos festivos. A média geral das duas campanhas foi de $20,32 \%$ do total da geração de resíduos. A este respeito, a literatura corrobora com o potencial de aproveitamento de materiais recicláveis, em percentuais que podem variar de $18 \%$ a $43,92 \%$ dos resíduos coletados em diversos estudos (TAVARES, 2008; KONRAD et al., 2010; GALLARDO et al., 2016; RAMACHANDRA et al., 2018).

Tabela 4: Materiais recicláveis.

\begin{tabular}{|c|c|c|c|c|c|c|c|c|c|}
\hline \multicolumn{10}{|c|}{ Junho, Julho, Agosto } \\
\hline Materiais & RA 1 & RA 2 & RA 3 & RA 4 & RA 5 & RA 6 & RA 7 & RA 8 & Média \\
\hline Papel & $6,00 \%$ & $0,50 \%$ & $3,00 \%$ & $1,50 \%$ & $2,00 \%$ & $4,50 \%$ & $4,00 \%$ & $5,50 \%$ & $3,38 \%$ \\
\hline Papelão & $4,00 \%$ & $4,50 \%$ & $4,10 \%$ & $4,00 \%$ & $1,50 \%$ & $3,50 \%$ & $8,00 \%$ & $2,50 \%$ & $4,01 \%$ \\
\hline Plástico Duro & $2,00 \%$ & $2,50 \%$ & $2,90 \%$ & $2,00 \%$ & $0,50 \%$ & $2,00 \%$ & $3,50 \%$ & $2,50 \%$ & $2,24 \%$ \\
\hline Plástico Mole & $8,00 \%$ & $2,90 \%$ & $7,50 \%$ & $11,00 \%$ & $4,50 \%$ & $8,00 \%$ & $4,50 \%$ & $1,35 \%$ & $5,97 \%$ \\
\hline \multicolumn{2}{|l|}{ Latas de alumínio } & & & & & $0,10 \%$ & & & $0,10 \%$ \\
\hline Metais Ferrosos & $1,25 \%$ & $0,60 \%$ & $3,00 \%$ & $0,30 \%$ & $1,50 \%$ & $0,40 \%$ & $0,25 \%$ & $0,60 \%$ & $0,99 \%$ \\
\hline Metais não Ferrosos & $0,20 \%$ & $0,32 \%$ & $0,50 \%$ & $0,30 \%$ & $1,50 \%$ & $0,90 \%$ & $0,30 \%$ & $2,50 \%$ & $0,82 \%$ \\
\hline \multirow[t]{2}{*}{ Vidro } & & $0,63 \%$ & $0,50 \%$ & & $2,00 \%$ & $0,60 \%$ & $0,20 \%$ & $1,25 \%$ & $0,86 \%$ \\
\hline & $21,45 \%$ & $11,95 \%$ & $21,50 \%$ & $19,10 \%$ & $13,50 \%$ & $20,00 \%$ & $20,75 \%$ & $16,20 \%$ & $18,06 \%$ \\
\hline \multicolumn{10}{|c|}{ Novembro, Dezembro, Janeiro } \\
\hline Papel & $4,50 \%$ & $3,80 \%$ & $4,50 \%$ & $5,30 \%$ & $6,90 \%$ & $0,50 \%$ & $6,50 \%$ & $5,50 \%$ & $4,69 \%$ \\
\hline Papelão & $5,60 \%$ & $3,90 \%$ & $5,50 \%$ & $7,80 \%$ & $6,50 \%$ & $4,50 \%$ & $6,00 \%$ & $3,50 \%$ & $5,41 \%$ \\
\hline Plástico Duro & $2,10 \%$ & $4,05 \%$ & $6,20 \%$ & $4,20 \%$ & $3,70 \%$ & $4,50 \%$ & $4,90 \%$ & $3,00 \%$ & $4,08 \%$ \\
\hline Plástico Mole & $3,30 \%$ & $6,92 \%$ & $7,70 \%$ & $5,40 \%$ & $5,80 \%$ & $6,45 \%$ & $5,90 \%$ & $1,95 \%$ & $5,43 \%$ \\
\hline Latas de alumínio & $0,25 \%$ & $0,13 \%$ & $0,10 \%$ & $0,10 \%$ & $0,20 \%$ & & & $0,05 \%$ & $0,14 \%$ \\
\hline Metais Ferrosos & $0,30 \%$ & $0,80 \%$ & $1,60 \%$ & $1,40 \%$ & $2,62 \%$ & $1,25 \%$ & $0,70 \%$ & $2,00 \%$ & $1,33 \%$ \\
\hline Metais não ferrosos & $0,25 \%$ & $0,40 \%$ & $0,20 \%$ & $0,75 \%$ & $0,80 \%$ & $0,80 \%$ & $1,20 \%$ & $1,00 \%$ & $0,68 \%$ \\
\hline \multirow[t]{2}{*}{ Vidro } & $1,25 \%$ & $1,25 \%$ & $1,00 \%$ & $0,70 \%$ & $1,08 \%$ & $0,20 \%$ & $0,75 \%$ & $0,65 \%$ & $0,86 \%$ \\
\hline & $17,55 \%$ & $21,25 \%$ & $26,80 \%$ & $25,65 \%$ & $27,60 \%$ & $18,20 \%$ & $25,95 \%$ & $17,65 \%$ & $22,58 \%$ \\
\hline
\end{tabular}

\section{Rejeitos}

Durante a coleta de dados dos meses de junho, julho e agosto foi possível identificar nas 8 regiões administrativas a média de massa percentual de rejeitos de 13,64\%. Esse percentual é próximo do que a literatura apresenta em diversos trabalhos sobre variabilidade de potencial de aproveitamento de materiais recicláveis, com percentuais entre $18 \%$ e $43,92 \%$ dos resíduos coletados em diversos estudos (TAVARES, 2008; KONRAD et al., 2010; MOURA et al., 2018).

Percebeu-se pouca variabilidade nos períodos de amostragens, o que pode ser justificado pelas semelhanças de hábitos e costumes. Os materiais que mais se destacaram foram fraldas $(5,70 \%)$, trapos (4,22\%). As fraldas representam o maior valor médio percentual, pois têm um consumo crescente em todos os níveis socioeconômicos, persistindo no meio ambiente mesmo após seu uso e, consequentemente, ocasionando impactos ao meio ambiente. Corroborando com o estudo, Oliveira et al. (2017) sobre avaliação gravimétrica de resíduos sólidos, encontrou para este material o percentual de $11 \%$ (usando o termo tecidos) dos resíduos coletados. Observa-se que esse componente corresponde a roupas usadas, disposta no lixo, mesmo sendo artigos escassos para população menos favorecida. Com a crise econômica, é comum encontrar roupas com preços atraentes, como os casos de lojas que vendem 'qualquer peça' por $\mathrm{R} \$ 10,00$, $R \$ 12,00$ e/ou $R \$ 15,00$; essas peças, após o uso, geralmente são descartadas sem que a doação, a reutilização ou a reciclagem sejam consideradas. Na reciclagem, os materiais poderiam ser transformados em fibra têxtil, que poderia ser usada como matéria-prima no processo produtivo. 
Políticas públicas de informação, aliadas à conscientização ambiental da população sobre o descarte correto, seriam alternativas para a mudança de hábitos, tornando-os mais sustentáveis. No entanto, "esta situação sobrecarrega economicamente e operacionalmente o sistema de seletivo de coleta, além de enviar resíduos perigosos ao aterro sanitário" (MOURA et al., 2018).

Dentre os materiais que tiveram menores percentuais nas amostras coletadas estão a borracha $(0,01 \%)$, as terras e similares, terra, brita, cimento, concreto, etc., $(1,18 \%)$, o papel higiênico e o absorvente $(0,27 \%)$ e os couros $(0,24 \%)$. O baixo valor registrado no item terras e similar coincide com o período de diminuição das atividades do setor de construção civil popular. Constata-se, ainda, que a categoria de outros elementos obteve percentuais próximos de zero, o que demonstra que a sua presença no mês de agosto foi quase nula, devido às pessoas terem os hábitos de queimar alguns materiais, como é o caso do papel higiênico e do absorvente.

Durante os meses de novembro, dezembro 2017 e janeiro 2018 foi possível identificar nas 8 regiões administrativas a média de massa percentual de rejeitos de $10,82 \%$. Os materiais que mais se destacaram foram os trapos e fraldas, com percentuais de $5,03 \%$ e de $3,70 \%$, respectivamente. Percebe-se que o item trapos teve média superior no mês de agosto, com 4,22\%, o que é inversamente proporcional à sazonalidade. É possível que a aquisição de roupas ocorra com maior intensidade nesse período, e que o excedente deste material seja descartado no ciclo seguinte, sendo depositado no lixo comum, mesmo que pudesse ser reaproveitado, reciclado, "distribuídos ou vendidos como itens de segunda mão" (GOMEZ et al., 2009). A geração de resíduos sólidos urbanos aumenta consideravelmente como consequência do consumo desenfreado. Além disso, a diversidade de materiais contida nos resíduos exige uma cobertura consistente dos sistemas de gerenciamento de resíduos sólidos municipais (OJEDA-BENÍTZ et al., 2008).

Dentre os materiais que tiveram menores destaques nas amostras estão a madeira, o papel higiênico e o absorvente, a terra e seus similares, a borracha, o couro, com percentuais de $0,61 \%, 0,53 \%, 0,48 \%, 0,41 \%$ e $0,34 \%$, respectivamente. 0 item madeira, no entanto, não é gerado apenas nos domicílios, mas também na construção civil e, mesmo em quantidades baixas, podem ser aproveitados para fins energéticos. 0 percentual de papel higiênico e de absorvente foi inferior a 8\% (KONRAD et al., 2010; ADENIRAN et al., 2017). Observa-se, por fim, que a geração de resíduos está intimamente relacionada aos hábitos e costumes da população e à sazonalidade (Tabela 5).

Na classe de rejeitos, a média de massa referente à coleta nos meses de junho, julho e agosto foi de 13,64\%, enquanto a de novembro, dezembro 2017 e janeiro 2018 foi de 10,82\%, obtendo-se uma média geral de $12,23 \%$ nas duas campanhas. Muitos dos materiais presente na classe rejeitos poderiam ser encaminhados para reciclagem (KONRAD et al., 2010).

Os materiais potencialmente recicláveis representaram, em junho, julho e agosto, $18,06 \%$ do total da amostra. Em novembro, dezembro 2017 e janeiro 2018, o percentual foi de 22,58\%, o que leva a média geral para o percentual de 20,32\% dos resíduos sólidos gerados em Maceió. $O$ aumento percebido no mês de dezembro está provavelmente relacionado ao período festivo de final de ano. A composição gravimétrica a partir das análises sazonais pode contribuir para a quantificação dos materiais com potencial reciclável. 
Tabela 5: Materiais rejeitos.

\begin{tabular}{|c|c|c|c|c|c|c|c|c|c|}
\hline \multicolumn{10}{|c|}{ Junho, Julho, Agosto } \\
\hline Materiais & RA 1 & RA 2 & RA 3 & RA 4 & RA 5 & RA 6 & RA 7 & RA 8 & Média \\
\hline Madeira & & & $1,10 \%$ & & $0,50 \%$ & $4,70 \%$ & $0,75 \%$ & $5,00 \%$ & $2,41 \%$ \\
\hline Trapos & $2,80 \%$ & $13,80 \%$ & $3,40 \%$ & $2,70 \%$ & $2,00 \%$ & $4,10 \%$ & $2,35 \%$ & $2,60 \%$ & $4,22 \%$ \\
\hline Couros & & & & $0,30 \%$ & $0,30 \%$ & $0,20 \%$ & $0,20 \%$ & $0,20 \%$ & $0,24 \%$ \\
\hline Borracha & & & $3,50 \%$ & $1,20 \%$ & & $0,30 \%$ & $2,00 \%$ & $0,30 \%$ & $1,46 \%$ \\
\hline Terras e similares & $0,90 \%$ & $0,80 \%$ & & & $4,10 \%$ & $0,30 \%$ & $0,50 \%$ & $0,50 \%$ & $1,18 \%$ \\
\hline Fraldas & $3,00 \%$ & $1,50 \%$ & $14,50 \%$ & $8,00 \%$ & $6,10 \%$ & $9,00 \%$ & $1,00 \%$ & $2,50 \%$ & $5,70 \%$ \\
\hline Papel higiênico e absorvente & $0,20 \%$ & $0,20 \%$ & $0,10 \%$ & $0,30 \%$ & $0,10 \%$ & $0,70 \%$ & $0,15 \%$ & $0,40 \%$ & $0,27 \%$ \\
\hline & $6,90 \%$ & $16,30 \%$ & $22,60 \%$ & $12,50 \%$ & $13,10 \%$ & $19,30 \%$ & $6,95 \%$ & $11,50 \%$ & $13,64 \%$ \\
\hline \multicolumn{10}{|c|}{ Novembro, Dezembro, Janeiro } \\
\hline Madeira & $0,10 \%$ & $2,00 \%$ & & $0,20 \%$ & $0,25 \%$ & $0,50 \%$ & $0,60 \%$ & & $0,61 \%$ \\
\hline Trapos & $3,80 \%$ & $4,10 \%$ & $7,50 \%$ & $4,10 \%$ & $3,90 \%$ & $10,80 \%$ & $3,75 \%$ & $2,30 \%$ & $5,03 \%$ \\
\hline Couros & $0,20 \%$ & $0,20 \%$ & $0,10 \%$ & $0,30 \%$ & $0,20 \%$ & $1,00 \%$ & $0,25 \%$ & $0,50 \%$ & $0,34 \%$ \\
\hline Borracha & $0,30 \%$ & $0,10 \%$ & $0,30 \%$ & $0,50 \%$ & $0,25 \%$ & $0,20 \%$ & $1,00 \%$ & $0,60 \%$ & $0,41 \%$ \\
\hline Terras e similares & $0,40 \%$ & $0,25 \%$ & & $0,50 \%$ & $0,30 \%$ & $0,45 \%$ & $0,95 \%$ & & $0,48 \%$ \\
\hline Fraldas & $4,55 \%$ & $2,60 \%$ & $4,50 \%$ & $4,00 \%$ & $2,40 \%$ & $4,70 \%$ & $3,05 \%$ & $3,80 \%$ & $3,70 \%$ \\
\hline \multirow[t]{2}{*}{ Papel higiênico e absorvente } & $0,20 \%$ & $0,20 \%$ & $0,30 \%$ & $0,85 \%$ & $0,70 \%$ & $0,45 \%$ & $0,75 \%$ & $0,75 \%$ & $0,53 \%$ \\
\hline & $9,55 \%$ & $9,45 \%$ & $12,70 \%$ & $10,45 \%$ & $8,00 \%$ & $18,10 \%$ & $10,35 \%$ & $7,95 \%$ & $10,82 \%$ \\
\hline
\end{tabular}

As informações referentes à primeira análise realizada mostraram que em algumas regiões administrativas o percentual em massa de resíduos domésticos de origem orgânica foi predominante, expressando valores acima de 70,00\%. Apenas as RAs 3, 4 e 6 tiveram valores inferiores. Na segunda análise, entretanto, os percentuais de matéria orgânica diminuíram em relação à primeira análise. Apenas a RA-8, teve um percentual de $74,40 \%$. Observou-se, contudo, que todas as RAs apresentaram percentuais acima de $60,00 \%$.

Os materiais com potencial reciclável predominantes na primeira análise (junho, julho e agosto) foram o plástico mole, o papelão, o papel e o plástico duro, que é a mesma sequência encontrada em maior escala durante a segunda análise (novembro, dezembro e janeiro). Percebeu-se, entretanto, que houve redução nas tipologias de materiais recicláveis durante as duas coletas. Na classe rejeitos, os materiais predominantes da primeira análise foram às fraldas, os trapos e madeira, enquanto na segunda análise os materiais mais encontrados foram os trapos e as fraldas.

Nos dois processos de coleta de dados, os maiores percentuais encontrados são de matéria orgânica (67,45\%), que é um valor mais alto do que o encontrado em trabalhos semelhantes: para Gomes et al. (2009), o percentual foi de 45\%; já para Konrad et al. (2010), o percentual foi de 46\%; por fim, para Gomes et al. (2008), o valor foi de $48 \%$.

Em seguida, os materiais potencialmente recicláveis expressaram o percentual de $20,32 \%$ da massa percentual do total dos resíduos sólidos das duas amostras, diferentemente de outros trabalhos da área, que apresentaram percentuais de $18 \%$, 28\% e 43,92\% (GOMEZ et al., 2008; RAMACHANDDRA et al., 2018; GALLARDO, 2016).

O total de rejeitos foi de $12,23 \%$ do total das amostras, enquanto outros estudos sugerem percentuais de 6\% e de 30,5\% (KONRAD et al., 2010; MOURA et al., 2018). Estilo de vida, padrões de consumo e atividades econômicas são alguns dos fatores que estão entrelaçados à produção e às quantidades de resíduos gerados em diferentes regiões geográficas mundiais. 


\section{CONCLUSÕES}

Diante dos resultados apresentados, foi possível observar na composição gravimétrica dos resíduos sólidos de origem doméstica nas regiões administrativas de Maceió que, o maior percentual foi de material orgânico (67,45\%). Ressalta-se que, além da possibilidade de geração de energia, o aproveitamento destes resíduos em processos de compostagem ou digestão anaeróbia podem reduzir significativamente a quantidade de lixo aterrado, aumentando a vida útil do aterro sanitário. Os compostos orgânicos resultantes destes processos podem ainda ser utilizados em jardins, praças, canteiros, além de poder oferecer ganhos com a comercialização dos produtos resultantes. Ao incorporar o processo de compostagem e/ou tratamento biológico anaeróbio (geração de biogás), gerenciamento de resíduos sólidos, possibilitam-se ganhos sociais, econômicos e ambientais.

Percebeu-se que, nas avaliações realizadas no aterro sanitário nos dois períodos de análises, a média percentual de material potencialmente reciclável foi de $20,32 \%$. Ressalta-se, portanto, que a coleta seletiva e a triagem dos resíduos podem ser ferramentas eficazes no reaproveitamento de resíduos recicláveis e consequente redução da quantidade de lixo aterrado.

A classe de rejeitos apresentou média percentual de 12,23\% na composição dos resíduos. O incentivo à reutilização de alguns desses materiais, como roupas e madeiras, poderiam ser alvo de ações educativas, com o intuito de despertar hábitos de consumo mais conscientes, reduzindo também, a destinação de resíduos para o do município de Maceió.

Por fim, ressalta-se a necessidade de investir em educação, conscientização ambiental, informação e promoção do bem-estar social, considerando o descarte e a separação adequada de resíduos sólidos domiciliares. Espera-se que, dessa forma, o presente trabalho possa contribuir com gestores públicos e pesquisadores da área na busca por alternativas e melhorias ambientais.

AGRADECIMENTO: à Coordenação de Aperfeiçoamento de Pessoal de Nível Superior - Brasil (CAPES) - Código de Financiamento 001.

\section{REFERÊNCIAS}

ABNT. Associação Brasileira de Normas Técnicas. NBR 10.004: Resíduos Sólidos. Rio de Janeiro: ABNT, 2004.

ABRELPE. Associação Brasileira de Empresas de Limpeza Pública e Resíduos Especiais. Panorama dos Resíduos Sólidos no Brasil. São Paulo: ABRELPE, 2016

ADENIRAN, A. E.; NUBI, A. T.; ADELEPO, A. O.. Solid waste generation and characterization in the University of Lago for a sustainable waste management. Waste Management, v.67, p.3-10, 2017. DOI:

https://doi.org/10.1016/j.wasman.2017.05.0022

AI-KHATIB, I. A.; MONOU, M.; ZAHARA, A. S. F. A.; SHAHEEN, H. Q.; KASSINOS, D.. Solid waste characterization, quantification and management practices in developing countries. A case study: Nablus district: Palestine. Journal of
Environmental Management, v.91, p.1131-1138, 2010. DOI: https://doi.org/10.1016/i.jenvman.2010.01.003

BARDIN, L.. Análise de conteúdo. São Paulo: Edições 70, 2011.

BEZERRA, C. R.; CAMPOS, K. F. S.. Avaliação da gestão e composição gravimétrica dos resíduos sólidos domiciliares do município de Manaíra/PB. InterEspaço, v.5, n.16 p.1-23, 2019. DOI: http://dx.doi.org/10.18764/2446$\underline{6549.2019 .10610}$

BRASIL. Lei n. 12.305, de 2 de agosto de 2010. Institui a Política Nacional de Resíduos Sólidos; altera a Lei no 9.605, de 12 de fevereiro de 1998; e dá outras providências. Brasília: DOU, 2010. 
BRASIL. Lei n. 9.605. Dispões sobe as sanções penais e administrativas derivadas de condutas de atividades lesivas ao meio ambiente, e dá outras providências. Brasília: DOU, 1998.

CAMPOS, H. K. T.. Renda e Evolução da Geração per capita de Resíduos Sólidos no Brasil. Eng. Sanit. Ambient., v.17, n.2, p.171-180, 2012

DEUS, R. M.; BATTISTELLE, R. A. G.; SILVA, G. H. R.. Current and Future Environmental Impact of Household Solid Waste Management Scenarios for a Region of Brazil: carbon dioxide and energy analysis. Journal of Cleaner Production, v.155, p.218-228, 2017. DOI:

https://doi.org/10.1016/j.jclepro.2016.05.158

FEAM. Fundação Estadual do Meio Ambiente. Cartilha de orientações: estudo gravimétrico de resíduos sólidos urbanos. Belo Horizonte, 2019.

FRANCO C. S.. Caracterização Gravimétrica dos Resíduos Sólidos Domiciliares Percepção dos Hábitos no Sul de Minas Gerais. Dissertação (Mestrado em Engenharia Agrícola) Universidade Federal de Lavras, Lavras, 2012.

GALLARDO, A.; EDO-ALCÒN, N.; CARLOS, M.; RENAU, M.. The determination of waste generation and composition as an essential tool to improve the waste management plan of a university. Waste Management, v.53, p.3-11, 2016. DOI: https://doi.org/10.1016/i.wasman.2016.04.013

GIL, A. C.. Métodos e técnicas de pesquisa social. 6 ed. Atlas Novo: São Paulo, 2008.

GOMES, L. P.; KOHI C. A.; SOUZA, C. L. L.; REMPEL, N.; MIRANDA, L. A. S.; MORAES, C. A. M.. Avaliação ambiental de aterros sanitários de resíduos sólidos urbanos precedidos ou não por unidades de compostagem. Eng Sanit Ambient v.20, n.3, p.449-462, 2015. DOI: https://doi.org/10.1590/S1413-41522015020000120751

GOMEZ, G.; MENESES, M.; BALINAS, L.; CASTELLS, F.. Characterization of urban solid waste in Chihuahua, Mexico. Waste Management, v.28, p.2465-2471, 2008. DOI: https://doi.org/10.1016/j.wasman.2007.10.023

GOMEZ, G.; MENESES, M.; BALINAS, L.; CASTELLS, F.. Seasonal characterization of municipal solid waste (MSW) in the city of Chihuahua, México. Waste Management, v.29, p.2018-2024, 2009. DOI: https://doi.org/10.1016/j.wasman.2009.02.006

KONRAD, O.; CASARIL, C. E.; SCHMITZ, M.. Estudo dos Resíduos Sólidos Domésticos de Lajeado/RS pela Caracterização Gravimétrica. Revista Destaques Acadêmicos, v.4, n.2, 2010.

LANDIM, A. P. M.; BERNARDO, C. O.; MARTINS, I. B. A.; FRANCISCO, M. R.; SANTOS, M. B.; MELO, N. R..

Sustentabilidade quanto às embalagens de alimentos no Brasil. Polímeros, v.26, p.82-92, 2016. DOI:

https://doi.org/10.1590/0104-1428.1897
MELO, E. N. C.. Levantamento Setorial da Produção Per Capita de Resíduos Sólidos Domésticos em Maceió/AL e Quantificação do Material Reciclável Retirado do Vazadouro de Lixo da Cidade. Dissertação (Mestrado em Gestão e Auditoria Ambiental) - Universidad de León, León, 2007.

MOURA, J. M. B. M.; PINHEIRO, I. G.; CARMO, J. L.. Gravimetric Composition of the Rejects Coming from the Segregation Process of the Municipal Recyclable Wastes. Waste Management, v.74, p.98-109, 2018. DOI: https://doi.org/10.1016/j.wasman.2018.01.011

NASCIMENTO, V. F.; SOBRAL, A. C.; ANDRADE, P. R.; OMETTO, J. P. H. B.. Evolução e desafios no gerenciamento dos resíduos sólidos urbanos no Brasil. Rev. Ambient. Água v.10, n.4, 2015. DOI: https://doi.org/10.4136/ambiagua. 1635

OJEDA-BENITZ, S.; VEJA, C. A.; MARQUEZ-MONTENEGRO, M. I.. Household solid waste characterization by family socioeconomic profile as unit of analysis. Recursos, Conservação e Reciclagem, v.52, p.992-999, 2008. DOI: https://doi.org/10.1016/j.resconrec.2008.03.004

OLIVEIRA, B. O. S.; OLIVEIRA, L. F.; MOURA, D. B.. Avaliação da composição gravimétrica dos resíduos sólidos gerados no conjunto Uruapiara do Município de Humaitá-AM. Scientia Amazônia, v.6, n2, p.58-62, 2017.

OZCAN, H. K.; GUVENC, S. Y.; GUVENC, L.; DEMIR, G. Municipal Solid Waste Characterization according to Different Income Levels: A Case Study. Sustainability, v.8, n.10, p.1044, 2016. DOI: https://doi.org/10.3390/su8101044

RAMACHANDRA, T. V.; BHARATHA, H. A.; KULKARNIA, G.; HAND, S. S.. Municipal solid waste: Generation, composition and GHG emissions in Bangalore, India. Renewable and Sustainable Energy Reviews, v.82, p.1122-1136, 2018. DOI: https://doi.org/10.1016/j.rser.2017.09.0855

RESENDE, J. H.; CARBONI, M.; MURGEL, M. A. T.; CAPPS, A. L. A. P.; TEIXEIRA, H. L.; SIMÕES, G. T. C.; RUSSI, R, R.; LOURENÇO, B. L. R.; OLIVEIRA, C. A.. Composição gravimétrica e peso específico dos resíduos sólidos urbanos em Jaú (SP). Eng. Sanit. Ambien., v.18 n, 1, p. 1-8, 2013.

SILVIA, L. R. C.; DAMACENO, A. D.; MARTINS, M. C. R.; SOBRAL, K. M.. Pesquisa Documental: Alternativa Investigativa na Formação do Docente. In: CONGRESSO NACIONAL DE EDUCAÇÃO, 9. Anais. Curitiba: PUCPR, 2009.

SOARES, E. L. S. F.. Estudo da Caracterização Gravimétrica e Poder Calorífico dos Resíduos Sólidos Urbanos. Dissertação (Mestrado em Engenharia Civil) - Universidade Federal do Rio de Janeiro, Rio de Janeiro, 2011.

TAVARES, J. C. L.. Caracterização dos Resíduos Sólidos Urbanos da Cidade de Maceió/AL. Dissertação (Mestrado em Recursos Hídricos e Saneamento) - Universidade Federal de Alagoas, Maceió, 2008.

A CBPC - Companhia Brasileira de Produção Científica (CNPJ: 11.221.422/0001-03) detém os direitos materiais desta publicação. Os direitos referem-se à publicação do trabalho em qualquer parte do mundo, incluindo os direitos às renovações, expansões e disseminações da contribuição, bem como outros direitos subsidiários. Todos os trabalhos publicados eletronicamente poderão posteriormente ser publicados em coletâneas impressas sob coordenação da Sustenere Publishing, da Companhia Brasileira de Produção Científica e seus parceiros autorizados. Os (as) autores (as) preservam os direitos autorais, mas não têm permissão para a publicação da contribuição em outro meio, impresso ou digital, em português ou em tradução. 